\title{
Myoclonus-Opsoclonus-Ataxia Syndrome Secondary to Advanced HIV Infection: A Rare and Atypical Case with Management Considerations
}

\author{
Ashley Ryan Vidad, OMS-III ${ }^{*}$, Ahjay Bhatia, OMS-III', Himadri Shah, OMS-III', Divy Mehra, OMS-III', \\ Shrinand Shah, OMS-I ${ }^{1}$ and Olu Ogunjemilusi, PGY-I
}

${ }^{1}$ Dr. Kiran C. Patel College of Osteopathic Medicine, Nova Southeastern University, Florida, USA

${ }^{2}$ Westside Regional Medical Center, Florida, USA

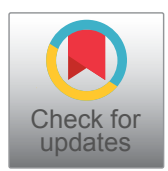

*Corresponding author: Ashley Ryan Vidad, OMS-III, Dr. Kiran C. Patel College of Osteopathic Medicine (KPCOM), Nova Southeastern University, 3200 S University Dr., Davie, FL 33328, USA, Tel: 650-307-7903

\begin{abstract}
Opsoclonus-myoclonus-ataxia syndrome (OMAS) is a rare but serious neurologic disorder that commonly presents with both spontaneous multidirectional saccades (opsoclonus) and involuntary shock-like muscular contractions (myoclonus), but may or may not present with ataxia. This disorder has an incidence of 0.18 cases per million in the total population but has a higher incidence of $0.27-0.40$ per million in children due to its link to specific pathologies [1]. OMAS is mostly idiopathic or associated with paraneoplastic syndromes such as neuroblastoma, small cell lung cancer, and ovarian cancer [2]. However, there have been few instances linking OMAS to infectious causes such as HIV $[3,4]$. This case presents an unusual presentation of OMAS with opsoclonus and ataxia without a myoclonic component in a previously healthy patient who was diagnosed with HIV after admission.
\end{abstract}

\section{Introduction}

Opsoclonus-myoclonus-ataxia syndrome (OMAS) is a rare disorder that presents with spontaneous arrhythmic, multidirectional saccades without a saccadic interval (opsoclonus) and rapid onset, brief, involuntary muscular contractions (myoclonus) which may or may not present with ataxia. Hence, this disease has been referred to as "dancing eyes, dancing feet". OMAS is mostly idiopathic in origin or in association with cancers such as neuroblastoma in children and breast and small cell lung cancer in adults [2]. However, other reports also link OMAS to infections such as Lyme disease, En- terovirus, West Nile virus, Salmonella, Cytomegalovirus, Coxsackievirus B3, streptococcus, and HIV [3-11]. OMAS commonly presents with both myoclonic and opsoclonic components, with or without ataxia. However, this case reports a previously healthy patient who presents with weakness, dizziness, balance dysfunction, gait instability, and multidirectional opsoclonus, without any spastic muscle contractions.

\section{Case Description}

Patient is a 43-year-old female with no past medical history, presented to the emergency department with complaints of weakness and dizziness for four days. She admits to decreased appetite, falling frequently, and a sensation that her eyes are moving. She denies fevers, chills, coughs, shortness of breath, chest pain, palpitations, abdominal pain, nausea, vomiting, difficulty swallowing, dysuria, rashes, seizures, or slurring of speech. Physical examination showed no abnormalities except for mild tachycardia, balance dysfunction, and nystagmus. She was awake, alert, oriented to person, place, and time. She has no motor deficits and sensation is intact. Initial Brain CT showed a small, age indeterminate, right frontal lobe infarction and aspirin was continued.

Throughout the course of the hospital stay, the patient develops extreme photophobia, diminished reflexes bilaterally, focal weakness, blurry vision, and diplopia, but is still alert, oriented to person, time, and 
place, and with gross sensation and CN II-XII still intact. Due to the downbeating nystagmus on ocular motility test, the neurologist considered a cervicomedullary junction pathology but head MRA showed no evidence of pathology and cervical spine MRI reported degenerative bulges at $\mathrm{C} 4-\mathrm{C} 5$ and $\mathrm{C} 5-\mathrm{C} 6$ junction, but otherwise negative. Due to the persistent ataxia and nystagmus, a history of heavy smoking, and weight loss, hematology and oncology was consulted and a paraneoplastic workup was done. However, paraneoplastic markers and antibodies such as rheumatoid factor, antinuclear antibody, Anti-Hu, Anti-Yo, and dsDNA were not detected.

Given her constantly low levels of WBC, an HIV workup was ordered and showed that the Antigen/Antibody HIV screen test was positive but HIV Antibody test was non-reactive, which was deemed as a probable false positive. The HIV-1 viral load was then checked and reported an HIV viral load of 427,459 copies/mL bDNA. At this point, a clinical picture of OMAS secondary to advanced HIV infection was elicited which prompted the start of the treatment for HIV with Raltegravir and Truvada (Emtricitabine and Tenofovir) and pulse high dose steroids for nystagmus. Patient reported mild alleviation of the nystagmus but persisted until discharge.

\section{Discussion}

Opsoclonus myoclonus ataxia syndrome is an extremely rare neurological disorder that usually presents idiopathic or as a paraneoplastic syndrome. Its reported incidence is 1 case for every $10,000,000$ in the total population but is slightly higher in children. Idiopathic OMAS presents in younger adult patients and have a better clinical outcome compared to paraneoplastic OMAS that presents in older adult patients around the age of 50 [12]. This disease has no apparent predilection for any race and ethnicity but there are $10 \%$ more females than males who suffered from OMAS [2].

In most patients with idiopathic OMAS, there are no associated autoimmune antibodies [13]. However, there are OMAS cases where antibodies have been linked with specific neoplasms such as anti-Ri antibody with breast cancer and Anti-Hu and Anti-Glycine receptor (Gly-R) antibody with small cell lung cancer $[13,14]$. Other autoimmune markers reported are directed against neuronal surface antigens such as dipeptidyl-peptidase-like protein-6 (DPPX), antibodies to non-synaptic surface puncta on neuronal dendrites, glutamic acid decarboxylase (GAD), gamma-aminobutyric acid type $A$ (GABA-A) and type $B(G A B A-B)$ receptors, N-methyl-D-aspartate receptor (NMDAR), and antibodies against the surface of cerebellar granular neurons [13,15-19]. In paraneoplastic OMAS, bladder cancer, gastric adenocarcinoma, ovarian teratoma, and malignant melanoma have been associated with this syndrome [12,20-22].

Although rare, OMAS can lead to pervasive and permanent neurological deficits such as dysregulated be- haviors and affect, irritability, poor attention, impulsivity, and cognitive impairment [23]. Thus, early detection and treatment of the underlying pathology is essential and has improved OMAS and its neurologic sequelae [24]. In the pediatric population, the most commonly prescribed treatments are $\mathrm{ACTH}$, steroids, and IVIg with ACTH having the best initial response [25]. Other cases also used azathioprine, cyclophosphamide, and plasmapheresis which also showed positive results [25]. In the adult population, immunotherapy is less effective but there have been responses to corticosteroids, cyclophosphamide, IVIg, clonazepam, and topiramate $[26,27]$. However, most adults who experience OMAS are more likely to have relapses [12]. There are ongoing Phase II clinical trials for the efficacy of rituximab for OMAS and also a Phase II clinical trial for carmustine, etoposide, cytarabine and melphalan together with antithymocyte globulin before a peripheral blood stem cell transplant $[28,29]$.

OMAS usually presents with both opsoclonic and myoclonic components, however this patient only complains of balance dysregulation and a sensation that her eyes are moving but denies any spastic muscle contractions. In addition, this patient has no past medical history which is an unusual presentation of OMAS due to its association to neoplasms. Even then, the paraneoplastic workup essentially came back negative but her low WBC and history of weight loss warranted an additional workup for HIV. In testing for OMAS, all possible etiologies should be considered even though the patient presentation does not perfectly fit the typical OMAS picture. This atypical presentation should be highlighted because early detection and treatment of OMAS proves to be essential in the prognosis of the syndrome and any attributed pathologies, which can affect the patient permanently throughout life.

\section{Conclusion}

OMAS typically presents with both opsoclonus and myoclonus, with optional ataxia. However, in patients who do not complain of spastic muscle contractions, OMAS should not be retracted from the differential diagnoses, especially in a patient with balance dysregulation. Moreover, OMAS can present in seemingly healthy patients. Early detection and treatment is empirical in this disease so a quick extensive workup should be started to decrease the chances of developing neurological deficits.

\section{Conflict of Interest}

The author(s) declare(s) that there is no conflict of interest.

\section{Author's Declaration}

The author(s) received no financial support for the research, authorship, and/or publication of this article. All authors contributed to the final manuscript. 


\section{References}

1. Pranzatelli MR, Tate ED, McGee NR (2017) Demographic, clinical, and immunologic features of 389 children with Opsoclonus-Myoclonus Syndrome: A cross-sectional study. Front Neurol 8: 468.

2. Digre KB (1986) Opsoclonus in adults. Report of three cases and review of the literature. Arch Neurol 43: 1165-1175.

3. Scott KM, Parker F, Heckmann JM (2009) Opsoclonus-myoclonus syndrome and HIV-infection. J Neurol Sci 284: 192-195.

4. Kanjanasut N, Phanthumchinda K, Bhidayasiri R (2010) HIV-related opsoclonus-myoclonus-ataxia syndrome: report on two cases. Clin Neurol Neurosurg 112: 572-574.

5. Peter L, Jung J, Tilikete C, Ryvlin P, Mauguiere F (2006) Opsoclonus-myoclonus as a manifestation of Lyme disease. J Neurol Neurosurg Psychiatry 77: 1090-1091.

6. Wiest G, Safoschnik G, Schnaberth G, Mueller C (1997) Ocular flutter and truncal ataxia may be associated with enterovirus infection. J Neurol 244: 288-292.

7. Alshekhlee A, Sultan B, Chandar K (2006) Opsoclonus persisting during sleep in West Nile encephalitis. Arch Neurol 63: 1324-1326.

8. Flabeau O, Meissner W, Foubert-Samier A, Guehl D, Desbordes $\mathrm{P}$, et al. (2009) Opsoclonus myoclonus syndrome in the context of Salmonellosis. Mov Disord 24: 2306-2308.

9. Zaganas I, Prinianakis G, Xirouchaki N, Mavridis M (2007) Opsoclonus-myoclonus syndrome associated with cytomegalovirus encephalitis. Neurology 68: 1636.

10. Kuban KC, Ephros MA, Freeman RL, Laffell LB, Bresnan MJ (1983) Syndrome of opsoclonus-myoclonus caused by Coxsackie B3 infection. Ann Neurol 13: 69-71.

11. Dassan P, Clarke C, Sharp DJ (2007) A case of poststreptococcal opsoclonus-myoclonus syndrome. Mov Disord 22: 1490-1491.

12. Bataller L, Graus F, Saiz A, Vilchez JJ (2001) Clinical outcome in adult onset idiopathic or paraneoplastic opsoclonus-myoclonus. Brain 124: 437-443.

13. Armangué $T$, Sabater L, Torres-Vega E, Martínez-Hernández E, Ariño H, et al. (2016) Clinical and immunological features of opsoclonus-myoclonus syndrome in the era of neuronal cell surface antibodies. JAMA Neurol 73: 417-424.

14. Luque FA, Furneaux HM, Ferziger R, Rosenblum MK, Wray SH, et al. (1991) Anti-Ri: An antibody associated with paraneoplastic opsoclonus and breast cancer. Ann Neurol 29: 241-251.

15. DeFelipe-Mimbrera A, Masjuan J, Corral Í, Villar LM, Graus F, et al. (2014) Opsoclonus-myoclonus syndrome and limbic encephalitis associated with GABAB receptor antibodies in CSF. J Neuroimmunol 272: 91-93.
16. Petit-Pedrol M, Armangue T, Peng X, Bataller L, Cellucci $\mathrm{T}$, et al. (2014) Encephalitis with refractory seizures, status epilepticus, and antibodies to the GABAA receptor: a case series, characterisation of the antigen, and analysis of the effects of antibodies. Lancet Neurol 13: 276-286.

17. Markakis I, Alexiou E, Xifaras M, Gekas G, Rombos A (2008) Opsoclonus-myoclonus-ataxia syndrome with autoantibodies to glutamic acid decarboxylase. Clin Neurol Neurosurg 110: 619-621.

18. Panzer JA, Anand R, Dalmau J, Lynch DR (2015) Antibodies to dendritic neuronal surface antigens in opsoclonus myoclonus ataxia syndrome. J Neuroimmunol 286: 86-92.

19. Blaes F, Fühlhuber V, Korfei M, Tschernatsch M, Behnisch W, et al. (2005) Surface-binding autoantibodies to cerebellar neurons in opsoclonus syndrome. Ann Neurol 58: 313317.

20. Pittock SJ, Lucchinetti CF, Lennon VA (2003) Anti-neuronal nuclear autoantibody type 2: paraneoplastic accompaniments. Ann Neurol 53: 580-587.

21. Fitzpatrick AS, Gray OM, McConville J, McDonnell GV (2008) Opsoclonus-myoclonus syndrome associated with benign ovarian teratoma. Neurology 70: 1292-1293.

22. Jung KY, Youn J, Chung CS (2006) Opsoclonus-myoclonus syndrome in an adult with malignant melanoma. J Neurol 253: 942-943.

23. Turkel SB, Brumm VL, Mitchell WG, Tavare CJ (2006) Mood and behavioral dysfunction with opsoclonus-myoclonus ataxia. J Neuropsychiatry Clin Neurosci 18: 239-241.

24. Takama Y, Yoneda A, Nakamura T, Nakaoka T, Higashio A, et al. (2016) Early detection and treatment of neuroblastic tumor with opsoclonus-myoclonus syndrome improve neurological outcome: A review of five cases at a single institution in Japan. Eur J Pediatr Surg 26: 54-59.

25. Tate ED, Allison TJ, Pranzatelli MR, Verhulst SJ (2005) Neuroepidemiologic trends in 105 US cases of pediatric opsoclonus-myoclonus syndrome. J Pediatr Oncol Nurs 22: 8-19.

26. Bartos A (2006) Effective high-dose clonazepam treatment in two patients with opsoclonus and myoclonus: GABAergic hypothesis. Eur Neurol 56: 240-242.

27. Fernandes TD, Bazan R, Betting LE, da Rocha FC (2012) Topiramate effect in opsoclonus-myoclonus-ataxia syndrome. Arch Neurol 69: 133.

28. (2021) Use of Rituximab in Opsoclonus-Myoclonus in children with Neuroblastoma. Identifier NCT00202930, ClinicalTrials.gov, Pittsburgh, PA.

29. (2020) Autologous peripheral blood stem cell transplant for Neurologic Autoimmune Diseases. Identifier NCT00716066, ClinicalTrial.gov, Denver, CO. 